\title{
A avaliação institucional como contexto e prática de planejamento: a experiência de uma rede municipal
}

\author{
Alessandra Rodrigues Almeida ${ }^{1}$ \\ Eliete Aparecida Godoy ${ }^{2}$ \\ Jussara Cristina Barboza Tortella ${ }^{3}$
}

\section{Resumo}

O texto trata de uma implementação da avaliação institucional como processo e instrumento de gestão e planejamento de uma rede municipal de ensino, por meio de formação de profissionais da educação, ao longo de 7 anos. Evidencia-se a experiência de gestão na qual esse tipo de avaliação foi entendido como uma maneira de compreender a realidade escolar, como mecanismo de participação e aprimoramento de políticas públicas que visam a qualidade educacional e a vivência democrática; agregando aos procedimentos a realização de diagnósticos, a coleta de dados, o desenvolvimento de ações e o planejamento e acompanhamento de políticas educacionais. Palavras-chave: Avaliação institucional; Gestão participativa; Políticas educacionais.

Institutional evaluation as context and planning practice: the experience of a municipal education network

\section{Abstract}

The text talks about an implementation of the institutional evaluation as a process and an instrument of management and planning of a municipal education network, through the training of education professionals, over 7 years. It is highlighted the management experience in which this type of evaluation was taken as a way of understanding the school reality, as a mechanism for participation and improvement of public policies that aims at educational quality and democratic living; adding to the procedures the accomplishment of diagnoses, the collection of data, the development of actions and the planning and follow up of educational policies.

Keywords: Institutional evaluation; Participatory management of education; Educational policies.

\section{Introdução}

A organização dos sistemas de ensino e das escolas para atender às demandas educacionais, em qualquer uma das esferas de governo (federal, estadual ou municipal), pressupõe planejamento, organização, direção, coordenação e controle, em um processo contínuo de revisão e reorganização, estabelecendo um sistema de ciclos. Tais aspectos se

\footnotetext{
1 PUC-Campinas, SP. alessandraalmeida628@gmail.com

2 PUC-Campinas, SP. elieteap.godoy@gmail.com

3 PUC-Campinas, SP. jussaratortella@gmail.com
}

Periódico Horizontes - USF - Itatiba, SP - Brasil - e019043 
materializam na formulação de políticas e no planejamento para a execução das mesmas.

A gestão do planejamento educacional e a organização do trabalho educativo abordam, de maneira ampla, a partir do princípio democrático, a necessidade de uma estrutura organizacional e de espaços institucionais compatíveis com a finalidade do trabalho pedagógico e com os objetivos educativos estabelecidos pela instituição, procurando aproximar a realidade existente de uma realidade desejada (GANDIN, 1994).

Nesse sentido, é fundamental que os gestores das escolas e das redes de ensino desenvolvam modos de planejar e avaliar a construção do projeto/política educacional em direção à sua finalidade, superando o modelo burocrático que situa o(a) Secretário(a) de Educação e o(a) Diretor(a) da Escola apenas como gerenciadores de rotinas e recursos. Para superar esse modelo, é importante que os gestores empreguem sua liderança na direção e na finalidade, dando ênfase aos processos democráticos e participativos. Neste texto discutiremos, em uma perspectiva construtiva e dialógica, a avaliação institucional como ferramenta de planejamento de política educacional de uma rede municipal de ensino do interior de São Paulo.

Ressalta-se que as autoras deste artigo atuaram na gestão dessa rede de ensino. A primeira autora como Assessora Técnica (8 anos) e Secretária de Educação (3 anos); a segunda como Secretária de Educação (8 anos); e a terceira autora atuou como Assessora Pedagógica (8 anos). Buscando articular os diferentes eixos do trabalho elegemos a avaliação institucional como um processo e um instrumento de gestão, primeiramente, por considerarmos que sua estrutura contempla, inicialmente, indicadores relacionados ao acesso à escola, com o fluxo e com o desempenho escolar. Tais informações são importantes referências para deflagrar a elaboração do Plano Municipal de Educação (PME), que também se constitui em um elemento de planejamento, acompanhamento, compromisso e prestação de contas de políticas públicas implantadas ou não. Em segundo lugar, porque é parte integrante da política educacional, desde a sua formulação até seus eventuais impactos, e como um mecanismo que favorece o diálogo e participação de diferentes atores na discussão e desenvolvimento de uma escola com qualidade social. Por fim, por acreditarmos que o delineamento de uma política pública deva iniciar-se na autoavaliação da escola, traçando uma estratégia interna prevista em seu Projeto PolíticoPedagógico (PPP), que precisa ser articulada com uma política mais ampla, prevista em Periódico Horizontes - USF - Itatiba, SP - Brasil - e019043 
documentos legais municipais, como o Plano Municipal de Educação (PME) e também diretrizes amplas como a Lei de Diretrizes e Bases da Educação Nacional (BRASIL, 1996), entre outros.

A concepção que orientou a experiência ancora-se no planejamento estratégico e participativo. O foco do planejamento estratégico está no conteúdo, orientação para resultados da organização, com forte visão de futuro (LÜCK, 2000). O planejamento participativo ocorre por meio da criação de mecanismos institucionais que possibilitem às pessoas se reunirem em torno de temas consensuais, expondo seus pontos de vista e deliberando coletivamente sobre questões de interesse comum (LÜCK et al., 2005).

Para Souza et al. (2005), o planejamento participativo envolve quatro dimensões: o processo de construção e desenvolvimento de ações, que não são adquiridas por atos jurídicos ou decretos; a caracterização participativa que deve ter como objetivo a participação plena e irrestrita de todos os agentes; o meio, pois constrói-se participação participando, e a práxis, participação cuja prática tem um caráter político.

A compreensão de avaliação institucional que norteou a experiência fundamenta-se no olhar da instituição sobre si mesma, num processo de construção de conhecimento sobre sua própria realidade, envolvendo discussões e reflexões sobre o quê e por quê fazer, definindo as ações e maneiras de acompanhá-las ao longo do tempo (SORDI; BERTAGNA; SILVA, 2016).

O que se pretende com este artigo é apresentar considerações sobre as condições peculiares de um contexto, focando na avaliação institucional, em sua implementação, execução e nos resultados obtidos. Isto ocorre a partir da concepção de que a avaliação não pode ser entendida como um mero processo burocrático inerente à gestão da educação, como uma atividade pontual, mas que pode ser delineada de forma sistemática, abarcando os diferentes momentos de realização da política pública.

\section{O contexto e os primeiros passos no desenvolvimento da experiência}

A Rede Municipal de Educação, onde a experiência foi realizada, existe desde 1962, atuando no atendimento de alunos de educação infantil e, em 1997, passou a ofertar o Ensino Fundamental. O sistema de ensino era formado por 25 escolas, constituídas em: Centro Periódico Horizontes - USF - Itatiba, SP - Brasil - e019043 
Integrado Municipal de Ensino (CIME), unidades que atendiam mais de um segmento de ensino, como Educação Infantil e Ensino Fundamental; Escola Municipal de Educação Infantil (EMEI) que atendia exclusivamente Educação Infantil; e Escola Municipal (EM) que atendia apenas o Ensino Fundamental ou agregava também a Educação de Jovens e Adultos. No referido município, as autoras atuaram na gestão da educação por onze anos, e o relato se refere ao processo desenvolvido no período de 2005 a 2011.

O Programa de Avaliação Institucional na Rede de Ensino Municipal foi delineado como uma política de gestão que objetivou conhecer de forma sistemática a realidade das escolas municipais, incentivando a participação de seus profissionais de forma responsável e efetiva. Tal programa foi construído a partir de discussões coletivas em seminários e oficinas realizadas junto com os integrantes das escolas, bem como em encontros dos conselhos municipais vinculados à educação, a partir dos seguintes objetivos gerais:

- Caracterizar e analisar a realidade, contemplando a sistematização de dados acerca da realidade educacional da rede, integrando o diagnóstico e dando suporte aos debates coletivos;

- Promover a aprendizagem para a avaliação com o intuito de desenvolver uma cultura de avaliação pela rede municipal de ensino, implantando um processo contínuo;

- Planejar e redirecionar as ações da rede municipal de ensino a partir da avaliação institucional;

- Construir um planejamento institucional norteado pela gestão democrática e autônoma; Definidos os objetivos principais, foi organizado um grupo de trabalho (GT) para efetivamente implementar a avaliação institucional na rede municipal de ensino. Tal grupo foi constituído pela assessoria técnica e pedagógica da Secretaria de Educação, por supervisores pedagógicos, diretores de escolas e professores, todos selecionados a partir da manifestação de interesse e da indicação de seus pares em consulta realizada nas escolas da rede.

A implantação da avaliação institucional foi desenvolvida em três etapas que envolveram o planejamento e preparação para o processo coletivo, o desenvolvimento efetivo da avaliação nas/pelas escolas e a consolidação do processo com previsão de revisão e redirecionamento. Essas etapas são detalhadas na sequência.

Periódico Horizontes - USF - Itatiba, SP - Brasil - e019043 
Etapa I - planejamento e preparação para o processo coletivo

O objetivo desta etapa, iniciada em 2005, foi planejar a avaliação institucional, estimular e envolver os atores no processo. Previram-se as seguintes ações:

a) Reuniões do Grupo de Trabalho de Avaliação, com a função de coordenar e articular o processo da avaliação institucional;

b) Estudos, reflexões e debates a respeito da avaliação institucional e sua relação com o autoconhecimento da escola e com o planejamento de políticas públicas;

c) Planejamento da implantação da avaliação com a definição de objetivos, estratégias, metodologia, recursos e cronograma das ações a serem realizadas;

d) Sensibilização das comunidades escolares buscando o envolvimento com o processo. Nos primeiros encontros do GT, foram apresentados questionamentos que mostraram os desafios a serem enfrentados e a necessidade de definição de um plano inicial de ações. As questões envolveram o conhecimento de alguns aspectos da realidade:

- O que as pessoas pensam sobre a educação do município? Por que afirmam o que afirmam? Em que direção podemos, juntos, definir as metas educacionais do município?

- Como estão as escolas nos aspectos físico, de gestão, financeiro e pedagógico?

- Em que medida as escolas, ao elaboraram seus projetos pedagógicos, implementam as ações previstas e as acompanham de forma participativa?

- Em que medida os conselhos funcionam com autonomia? E seus membros, verdadeiramente, representam os segmentos da comunidade escolar?

- Quais instrumentos ou procedimentos de gestão democrática existem nas escolas? Estes são meramente formais? Em que medida contribuem para que a participação real faça parte do cotidiano dos cidadãos envolvidos?

Esses questionamentos foram levantados com base em informações obtidas por meio de documentos elaborados pelas escolas, pelas informações discutidas pelos participantes considerando suas experiências. Não foram encontradas respostas únicas para tais questões, os mecanismos de participação, os estilos de gestão e a compreensão do papel da escola eram distintos em cada unidade.

Não tínhamos o intuito de homogeneizar os procedimentos ou definir metas e objetivos Periódico Horizontes - USF - Itatiba, SP - Brasil - e019043 
iguais para escolas com realidades e condições de funcionamento desiguais, sem respeitar a identidade e a forma de atendimento de cada uma. Entretanto, precisaríamos negociar com o grupo alguns aspectos comuns para as escolas da rede. Nesse sentido, buscamos explicitar e definir, de modo consensual, valores, objetivos, prioridades e ideias sobre como eram as escolas, e também sobre como elas deveriam ou poderiam ser.

Etapa II - desenvolvimento da avaliação na/com a escola

O objetivo desta etapa foi a concretização das atividades que foram programadas na proposta de avaliação institucional. Previram-se as seguintes ações:

a) Definição de cronograma e ações do Grupo de Trabalho;

b) Realização das atividades programadas como: grupos de estudos, seminários, painéis de discussão, reuniões técnicas e sessões de trabalho;

c) Construção dos instrumentos de avaliação - indicadores como medida quantitativa e qualitativa;

d) Definição de recursos necessários ao desenvolvimento da avaliação;

e) Aplicação dos instrumentos de avaliação;

f) Definição da metodologia de análise e interpretação de dados;

g) Elaboração dos relatórios de avaliação.

Os encontros e discussão do GT se materializaram em documentos que definiram os instrumentos e métodos de coleta de informações para compor a avaliação institucional, em seu momento inicial denominada "autoavaliação da escola". Era entendida como o "olhar" da instituição sobre si mesma, como processo de construção de conhecimento das pessoas que fazem parte da instituição, a fim de orientar as tomadas de decisão na busca do comprometimento com a melhoria da qualidade da Educação.

O GT discutiu os eixos de avaliação, as questões e a ponderação dos resultados. Além disso, definiu os momentos em que seriam realizadas as atividades de avaliação, bem como quem seriam os participantes desse processo, representantes de todos os servidores da escola.

A avaliação foi organizada com itens afirmativos que deveriam ser pontuados de 1 a 5 , no modelo de Escala Likert, e orientada a partir de cinco dimensões: Órgãos Colegiados de Gestão, 
com 17 itens; Profissionais da Educação, com 08 itens; Condições Físicas e Materiais, com 13 itens; Prática Pedagógica, com 39 itens; e Ambiente Educativo, com 13 itens. Esse instrumento de avaliação, depois de discutido e preenchido por representantes das escolas, era apresentado à SME para análise e utilizado para subsidiar a elaboração de plano de ação das respectivas escolas para superação das dificuldades encontradas.

O instrumento de autoavaliação e o processo de discussão sobre os assuntos apontados no documento, bem como o preenchimento das informações por representantes de cada escola ocorreu em 2005 e em 2006; porém, no início do ano seguinte, os profissionais das escolas e da SME apontaram algumas fragilidades do processo de avaliação e do instrumento, dentre os quais estavam os profissionais que não se sentiam representados pelo grupo que participava do processo de avaliação e a extensão do instrumento, o que dificultava o aprofundamento do debate de assuntos importantes. Cabe ressaltar que os profissionais representantes das escolas foram escolhidos de forma democrática, sendo que as pessoas que tinham interesse se inscreviam e os demais profissionais da escola faziam sua indicação dentre esses inscritos. No entanto, a maior parte dos profissionais consideraram que a participação por meio da representação não era suficiente, e evidenciaram que todos eles deveriam participar da avaliação institucional.

Esses apontamentos geraram a necessidade de uma nova organização dos profissionais para revisão do instrumento e do processo de avaliação, o que consideramos como a terceira etapa do processo de avaliação institucional, detalhada a seguir.

Etapa III - consolidação do processo e novos direcionamentos

Após dois anos de estudos e implementação de ações para viabilizar a avaliação institucional, em 2007, o GT deu continuidade aos trabalhos com o intuito de consolidar o processo avaliativo, redirecionar as ações e efetivar a articulação entre a avaliação e o planejamento de ações, tanto no nível micro, da escola, quanto macro, da rede. O objetivo desta etapa foi incorporar os resultados encontrados na avaliação e buscar, através destes, a melhoria da qualidade da educação municipal. Previram-se as seguintes ações:

a) Organização das discussões dos resultados pelas comunidades escolares;

b) Elaboração de um relatório que sistematizou os resultados das discussões, a análise e

Periódico Horizontes - USF - Itatiba, SP - Brasil - e019043 
interpretação dos dados para compor o Plano Municipal de Educação e Plano de Ações Articuladas -PAR

c) Participação na organização e desenvolvimento da I Conferência Municipal de Educação;

d) Definição de planos para a gestão e supervisão com o intuito de prospectar ações a partir dos resultados das avaliações, visando o saneamento das deficiências encontradas;

e) Articulação entre os resultados das avaliações institucionais e os Projetos PolíticoPedagógicos (PPPs) das escolas;

f) Redirecionamento do instrumento e procedimentos de avaliação, visando torná-la um processo ainda mais democrático e coerente com a realidade das escolas.

Nesta etapa, o GT analisou o instrumento existente, promoveu alterações e definiu que todos os profissionais da escola deveriam participar da avaliação e respondê-lo, com intuito de ampliar as discussões e de propor ações claras e coerentes para melhoria dos aspectos frágeis, planejar ações para o ano subsequente, bem como revisar o Projeto Político Pedagógico.

O grupo elaborou um instrumento fundamentado nas dimensões: princípios norteadores do Projeto Político Pedagógico; estrutura física; prática pedagógica; rendimento escolar; gestão democrática; formação e condições de trabalho dos profissionais da escola; parceria escola/SME; e ensino e aprendizagem da leitura e escrita.

Em 2009, os profissionais das escolas e da SME sugeriram uma nova revisão do instrumento de Avaliação Institucional, de modo a contemplar novos aspectos e necessidades de articulação com planejamento das escolas e da SME. Diante dessa análise, retomou-se a organização do processo de avaliação institucional, visando ampliar o olhar sobre esse mecanismo de diagnóstico, valorizando a participação dos profissionais na reflexão e no debate sobre a escola, ensino e prática profissional. Assim, buscou-se assessoria junto à profissionais da Universidade Federal de São Paulo (UNIFESP) para a construção e análise dos indicadores produzidos até aquele momento, com o intuito de promover a formação e auxiliar nas discussões e contribuir com a qualificação do trabalho já realizado, respeitando o histórico de quatro anos que a rede municipal já possuía.

\footnotetext{
${ }^{4}$ É um instrumento de planejamento do Ministério da Educação (MEC) destinado ao desenvolvimento de ações conjuntas entre estado e municípios e que resultem em melhorias efetivas da qualidade da educação. Maiores informações podem ser acessadas em http://portal.mec.gov.br/par.
}

Periódico Horizontes - USF - Itatiba, SP - Brasil - e019043 
Após a organização do instrumento, foram realizadas reuniões com as equipes escolares, e posteriormente cada escola elegeu sua comissão representativa para: (a) retomar as discussões sobre a importância da avaliação institucional, em especial os aspectos de autoconhecimento e abertura para o diálogo; (b) reconhecimento da avaliação para melhoria da qualidade da escola; (c) qualificação do trabalho, permitindo reconhecer práticas que contribuíssem para melhoria dos resultados e redução da desigualdade de desempenho; (d) retomada das metas do Plano Municipal de Educação e das escolas; (e) contribuições para o planejamento, dialogando sobre o que poderia ser feito, quem deveria fazê-lo, onde as ações deveriam ser aplicadas, quando e como seriam realizadas; e (f) mecanismos para minimizar momentos de "incêndio" e sensação de eterno recomeço e para a melhoria nas relações e na comunicação.

O instrumento foi constituído por 23 itens que abordaram os princípios filosóficos da Proposta Político-Pedagógica, 44 relacionados à Prática Pedagógica, 17 sobre ensino aprendizagem de leitura e escrita, 20 enfatizando aspectos de avaliação, 31 relativos à gestão escolar democrática e 15 sobre formação e condições de trabalho dos profissionais.

$\mathrm{Na}$ experiência apresentada, vivenciamos a necessidade de alterar o processo avaliativo, em decorrência de diferentes fatores ao longo tempo, para que o processo e seus produtos fossem efetivamente úteis ao planejamento de políticas educacionais, e não meramente momentos formais, oficiais, sem uma análise aprofundada dos diagnósticos produzidos pelas escolas. Dentre esses fatores destacamos: clareza do que se pretendia medir; a qualidade e precisão das informações para compor os indicadores; cuidado e atenção na interpretação; democratização efetiva das informações de modo a permitir leitura da realidade; organização das informações de modo a ampliar o diálogo com os gestores da SME favorecendo participação dos profissionais nos processos de formulação monitoramento e avaliação de políticas públicas educacionais.

Ao analisar detalhadamente as dimensões destacadas nos instrumentos de avaliação, identificamos como maior necessidade de investimento por parte da SME questões relacionadas à dimensão da estrutura física das escolas, como: reformas e manutenções, logística da entrega de gêneros da merenda escolar, periodicidade de entrega de material de limpeza, manutenção de computadores, poda de árvores, aquisições de materiais, entre outros. Essas informações motivaram tanto a gestão municipal com a escolar a estruturar melhor as áreas administrativas 
responsáveis por essas questões, estabelecendo uma regularidade nas ações e melhorando a comunicação com as escolas em situações atípicas.

No aspecto pedagógico, as fragilidades destacadas referiam-se ao programa de educação inclusiva, em especial à dificuldade em socializar as reuniões de formações com toda a equipe, dificuldade de tempo para diálogo entre professores da sala regular e professores do Atendimento Educacional Especializado (AEE). No que se refere ao desempenho dos alunos, à prática pedagógica docente, ao resultado da escola em avaliações e índices de retenção, promoção e evasão, os profissionais das escolas não se detalhavam em informações sobre esses aspectos. Assim, a análise dos resultados dos alunos e a qualificação pedagógica do trabalho, aspectos diretamente ligados ao ensino e a aprendizagem, eram questionados pelas equipes gestoras e supervisão pedagógica.

A partir da organização dos dados, considerando os resultados gerais, as dimensões específicas, a análise da avaliação de cada escola e as comparações com os planos de trabalho do ano anterior, foi possível identificar, de modo mais claro e objetivo, as potencialidades e fragilidades de cada unidade, de cada equipe e da própria SME. Essas informações subsidiaram o planejamento e a tomada de decisão para o desenvolvimento de políticas educacionais, ações educativas e outros aspectos, tanto para os profissionais que atuavam nas escolas quanto para os gestores da SME.

Ressalta-se que o Ministério da Educação disponibilizou o Plano de Ações Articuladas (PAR) aos gestores municipais em abril de 2007, como um instrumento para avaliação e implementação de políticas para melhoria da qualidade de educação fundamentado em quatro dimensões: Gestão Educacional; Formação de Professores e dos Profissionais de Serviço e Apoio Escolar; Práticas Pedagógicas; e Avaliação. Entretanto, para que fosse possível preencher a base de dados de modo a realizar um plano com políticas públicas para educação, seria essencial que os gestores tivessem informações reais para realizar o diagnóstico. A avaliação institucional possibilitou a elaboração desse instrumento de forma efetiva, com base em dados e informações reais construídos coletivamente. Os representantes do GT de avaliação foram escolhidos por seus pares também para participarem da equipe local e do comitê local do PAR, pois eram reconhecidos pelo compromisso com o trabalho realizado no processo de implantação e desenvolvimento da avaliação institucional.

Periódico Horizontes - USF - Itatiba, SP - Brasil - e019043 
Consideramos importante destacar que a apresentação das etapas para implementação da avaliação institucional na rede foi descrita de modo a facilitar a compreensão do leitor de aspectos considerados relevantes no processo. Entretanto, muitas das discussões realizadas com foco em uma das etapas ocorreram também nas outras, como parte constituinte do processo: a realização de três Conferências Municipais de Educação e o Plano Municipal de Educação, que possibilitaram a expansão da participação, acompanhamento e avaliação da política educacional da rede municipal de ensino. No próximo tópico apresentamos principais conceitos e a experiência de uma avaliação institucional de uma rede municipal de educação.

\section{A avaliação institucional municipal: compreensões sobre a experiência desenvolvida}

Uma das perspectivas importantes para a experiência que descrevemos é a relevância da avaliação para planejamento das políticas educacionais. Entendemos que o planejamento faz parte de um ciclo de ações na gestão educacional. O ciclo pode ser entendido como sendo a avaliação a primeira e/ou última etapa de ações.

Figura 1. Ciclo de planejamento e avaliação institucional colocada em prática

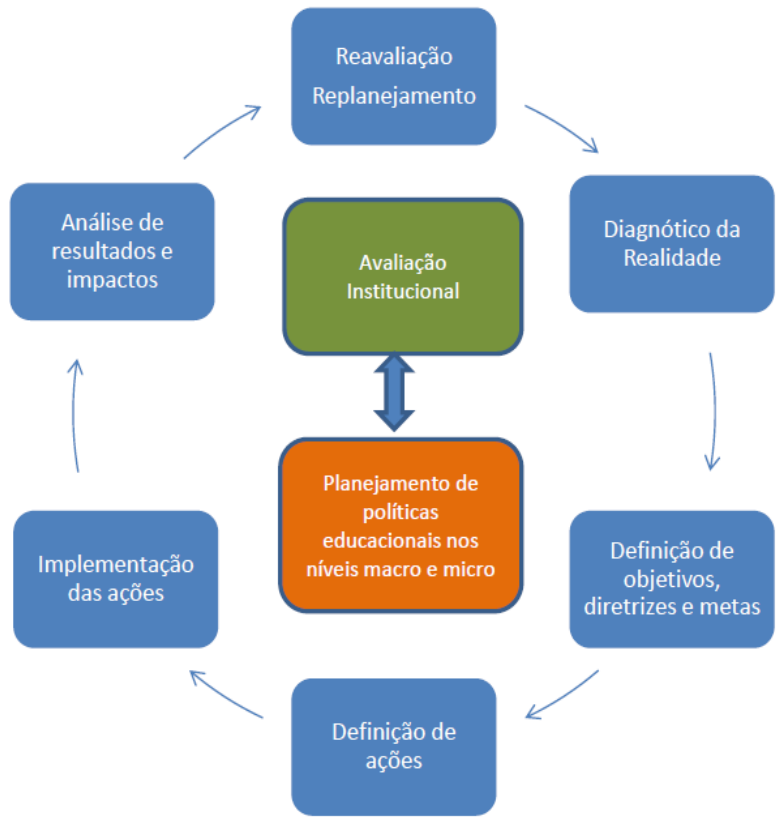

Fonte: Elaborada pelas autoras

Periódico Horizontes - USF - Itatiba, SP - Brasil - e019043 
A avaliação institucional é realizada com a finalidade de alimentar a tomada de decisões. No diagrama, apresentamos a articulação entre a avaliação institucional e o planejamento de políticas educacionais realizadas no nível das escolas (micro) e no âmbito do sistema de ensino como um todo, que compreende tanto a rede de escolas quanto as demais ações educacionais ou complementares de responsabilidade da gestão da educação municipal (macro).

Nesse ciclo, que articula avaliação institucional e planejamento, evidenciamos quatro aspectos importantes desenvolvidos nesse processo:

1) Momento de diagnóstico da realidade, que indicou problemas e potencialidades de cada instituição para estabelecimento de tomada de decisões com maior segurança.

2) Os atores envolvidos formularam objetivos, diretrizes e metas adequados aos problemas detectados, e definiram ações visando atingir os objetivos, indicando os responsáveis e os prazos para serem desenvolvidas.

3) Fase de implementação, que teve por finalidade a execução e o acompanhamento das ações previstas, bem como aperfeiçoamento das mesmas.

4) A avaliação dos resultados e impactos, que buscou obter instrumentos para a tomada de novas decisões e/ou de prestar contas das ações desenvolvidas e encaminhamento para um novo processo, configurando-se como uma (re)avaliação e um (re)planejamento, iniciando um novo ciclo.

Ao abordarmos as dimensões inerentes ao planejamento participativo destacado por Souza et al (2005), observamos que o processo foi evidenciado durante a implantação da avaliação institucional, pois foram muitos os momentos de formação e produção desenvolvidos ao longo do tempo. Nesse sentido, os estudos e debates para que se chegasse a uma proposta de instrumento e procedimentos iniciais para a avaliação e os momentos posteriores de continuidade das discussões e redirecionamento das ações revelaram o movimento diacrônico instituído.

A característica da participação pôde ser observada pela organização de um grupo de trabalho formado por profissionais da escola e da secretaria, constituindo um grupo heterogêneo, que estudou e trabalhou cooperativamente. Os participantes do GT tiveram oportunidades de expor suas ideias e de propor ações, bem como de ser articuladores desse Periódico Horizontes - USF - Itatiba, SP - Brasil - e019043 
processo com os demais profissionais da escola e SME. A definição do GT de que todos os profissionais da escola deveriam estar envolvidos no processo de avaliação institucional revela o esforço de possibilitar a participação plena de todos os agentes.

O fato de que o planejamento deva ser uma ação, meio para construção da participação, é destacado como relevante no processo de implantação da avaliação, pela valorização das ações instituídas que foram tomadas como base para outras ações de participação como as conferências municipais de educação e comissões do PAR. Essas ações evidenciam não apenas as diferentes possibilidades de participação da comunidade escolar no planejamento de políticas educacionais municipais, mas também a dimensão da práxis (GRAMSCI, 1981), na qual a participação prática possui um caráter essencialmente político.

\section{Considerações finais}

A avaliação institucional proposta adotou uma metodologia participativa, buscando trazer para o âmbito das discussões as opiniões de todos os profissionais da educação, de forma aberta e cooperativa, e se deu globalmente e anualmente ao longo de sete anos. A metodologia proposta orientou o processo quanto às decisões, técnicas e métodos de forma flexível para, diante de situações concretas, assumirem novos contornos, adotar decisões e técnicas mais oportunas e diretamente vinculadas às situações em pauta.

A relação entre a teoria e a prática, ao descrever como a concepção de avaliação institucional e seu processo constitutivo permearam a experiência e caracterizaram um processo de concretização das intenções educativas, buscou cumprir os objetivos de identificar pontos fortes e frágeis; definir formas de ação para subsidiar a formulação de diretrizes para as políticas públicas de educação e, sobretudo, para a gestão das instituições escolares, visando a melhoria da qualidade da escola e do sistema educacional.

O processo de formação, as discussões com conselhos e profissionais da educação para construir, debater e estudar sobre a avaliação institucional, tanto no momento de concepção e implantação da avaliação institucional quanto no de organização e análise dos dados obtidos, possibilitou aos profissionais uma reflexão sobre sua própria atuação, seu papel na rede de 
ensino, mostrando a amplitude da educação municipal e, consequentemente, das diferentes frentes de atuação do supervisor na rede de ensino. Porém, é fundamental salientar que a atuação, o papel e a responsabilidade dos atores na consolidação das políticas públicas, com foco na qualidade do ensino, da democratização da gestão escolar e da formação humana são questões complexas, que merecem atenção e investimento da gestão municipal.

A avaliação institucional ainda requer muita atenção por parte dos gestores das escolas e da SME, para que se mantenha como mecanismo de diálogo e de propositura de ações para ampliar o processo de negociação responsável com as equipes escolares e comunidade sobre o seu projeto pedagógico, considerando suas necessidades e demandas e monitorando a qualidade, construída coletivamente.

\section{Referências}

BRASIL. Lei n. 9.394, de 20 de dezembro de 1996. Dispõe sobre as Diretrizes e Bases da Educação Nacional. Diário Oficial da União. Brasília, DF, 23 dez. de 1996.

GANDIN, D. A prática do planejamento participativo. Petrópolis: Vozes, 1994.

GRAMSCI, A. A Concepção Dialética de História. Rio de Janeiro, Civilização Brasileira, 4à. Edição, 1981.

LÜCK, H. A aplicação do planejamento estratégico na escola. Revista Gestão em Rede, n.19, p.813, 2000. Disponível em: <http://www.crmariocovas.sp.gov.br/pdf/luck_planejamento.pdf>. Acesso em: 15 ago. 2014.

LÜCK, H. et al. A escola participativa: o trabalho do gestor escolar. Petrópolis: Vozes, 2005. (Série Cadernos de Gestão). PADILHA, P. R. Planejamento dialógico: como construir o projeto político-pedagógico da escola. São Paulo: Cortez, 2001.

SORDI, M. R. L.; BERTAGNA, R. H.; DA SILVA, M. M. A Avaliação Institucional Participativa e os espaços políticos de participação construídos, reinventados, conquistados na escola. Cadernos Cedes, v. 36, n. 99, 2016.

SOUZA, Â. R. et al. Avaliação da aprendizagem, avaliação institucional e gestão escolar: a síntese necessária. In: Gestão e avaliação da educação escolar. Universidade Federal do Paraná, Pró-Reitoria de Graduação e Ensino Profissionalizante, Centro Interdisciplinar de 
Formação Continuada de Professores. Curitiba: Ed. da UFPR, 2005, v. 4. p.17- 22.

Recebido em abril de 2018.

Aprovado em junho de 2019.

Periódico Horizontes - USF - Itatiba, SP - Brasil - e019043 